\title{
IDENTITAS MEREK TUJUAN PARIWISATA DAN KERANGKA KERJA GAMBAR
}

\author{
Hifni Alifahmi \\ Sekolah Pascasarjana Universitas Sahid \\ Sahid Sudirman Residence, Jl. Jend. Sudirman No.86, Jakarta \\ Email Korespondensi: alifahmi21@yahoo.com
}

\begin{abstract}
ABSTRAK
Kementerian Pariwisata (Kemenpar) beberapa tahun terakhir ini cukup gencar melakukan kampanye pariwisata bertajuk Wonderful Indonesia atau Pesona Indonesia menawarkan sejumlah destinasi andalan. Kemenpar menetapkan sepuluh destinasi Bali baru sebagai prioritas, selain pulau Dewata. Untuk pengembangan destinasi wisata tentu tidak terlepas kaitannya dengan identitas dan citra destinasi wisata yang berujung pada upaya peningkatan jumlah kunjungan wisatawan. Karena itu, perlu dilakukan kajian untuk menelusuri konsep-konsep atau model-model pengembangan merek destinasi, terutama identitas dan citra destinasi pariwisata melalui studi literatur. Tujuan penelitian dengan studi literatur ini adalah untuk: 1) menelusuri beragam konsep dan model pengembangan merek destinasi pariwisata (destination brand development), termasuk elemen-elemen atau komponen merek destinasi (destination brand components); 2) menemukan dan merangkum model-model identitas dan citra merek destinasi pariwisata (tourism destination brand identity/image) beserta dimensi merek destinasidestination brand dimensions); dan 3) menyiapkan rancangan atau desain instrumen penelitian berdasarkan hasil penelusuran terhadap beragam konsep dan model identitas dan citra merek destinasi pariwisata. Pengumpulan data dilakukan melalui studi literaturterkait dengan tiga tujuan tersebut. Hasil penelitian ini adalah berupa pemaparan dan rangkuman beragam konsep atau model tentang identitas dan citra merek destinasipariwisata beserta desain instrumen yang diperlukan.
\end{abstract}

Kata Kunci: Merek destinasi, Komponen merek destinasi, Elemen merek destinasi, Identitas merek destinasi pariwisata, Citra merek destinasi pariwisata

\begin{abstract}
The Ministry of Tourism in recent years is quite incentive to conduct a tourism campaign titled "Wonderful Indonesia" or Pesona Indonesia offers a number of flagship destinations. The Ministry of Tourism set ten new Bali destinations as a priority, in addition to the island of Gods. Therefore, it is necessary to study to explore the concept or model of destination brand development, especially the identity and image of tourism destination through literature study. The purpose of the study with this literature study is to 1) exploring the various concepts and models of tourism destinations brand development including destination brand elements or components; 2) find and summarize the identity models and brand image of tourism destinations along with brand destination dimensions and 3) prepare the design or design of research instruments based on the results of research on various concepts and models of identity and brand image of tourism destinations. The data were collected through literature studies related to these three objectives. The results of this study are in the form of exposure and summary of various concepts or models about the identity and brand image of tourism destinations along with the necessary instrument design.
\end{abstract}

Keywords: Destination Brand, Destination Brand Components, Destination Brand Elements, Tourism Destination Brand Identity, Tourism Destination Brand Image 


\section{LATAR BELAKANG}

Indonesia adalah salah satu negara yang memiliki beragam destinasi pariwisata terindah di dunia. Berbekal ragam kekayaan destinasi pariwisata tersebut, Kementerian Pariwisata (Kemenpar) beberapa tahun terakhir ini cukup gencar melakukan kampanye pariwisata bertajuk Wonderful Indonesia atau Pesona Indonesia dengan menawarkan sejumlah destinasi pariwisata andalan. Salah satu materi kampanye pariwisata, yaitu video iklan Wonderful Indonesia: The Journey to Wonderful Worldbahkan meraih dua penghargaan dalam Festival Film Iklan Pariwisata 2017, sebuah ajang United Nations World Tourism Organization (UNWTO) Video Competition 2017 yang berlangsung di Chengdu, Cina.Dua kategori penghargaan yang diraih adalah video pariwisata terbaik di Asia Timur dan Pasifik, sertaPeople Choice Awardyang menjadiliputan berita pada 15 September 2017 lalu (www.travel.kompas.com). Kekuatan dan keindahan video iklan pariwisata tentu tidak bisa dipungkiri karena berkat dukungan gambar dan keindahan destinasi pariwisata yang ditampilkan dalam video.

Selaras dengan kampanye itu, konsekuensinya untuk menarik kunjungan wisatawan, maka destinasi pariwisata perlu benar-benar siap dan dikembangkan secara cermat. Salah satu literatur yang membahas proses pengembangan merek destinasi pariwisata adalah model Destination Brand Development, disingkat DEBRA dari Moilanen dan Rainisto (2009). Model DEBRA diawali denganrumusan Budaya Perusahaan, termasuk nilai-nilai dan perilaku. Lalu, Analisis Persepsi atau Citra merek destinasi dibandingkan pesaingnya di mata wisatawan maupun internal. Budaya perusahaan dan persepsi tersebut menjadi dasar untuk merumuskan Janji Merek Destinasi (Destination Brand Promise) atau Identitas Merek Destinasi (Destination Brand Identity)). Setelah itu, tiga langkah paralel: pengembangan proses pelayanan, pengembangan strategi komunikasi, dan pengembangan infrastruktur fisik.Berikutnya eksekusi eksternal komunikasi yang selaras dengan komunikasi internal, pelatihan, dan pelayanan. Terakhir,evaluasi untuk mencapaicitra merek destinasi holistik (Holistic Brand Image), sekaligus membandingkan antara pencapaian citra merek dengan identitas merek destinasi.

Tampaknya dalam kaitan pengembangan destinasi pariwisata seperti dalam model DEBRA itulah (yang menekankan pada kesesuaianantara citra merek dengan identitas merek destinasi), Kemenpar menetapkan sepuluh destinasi Bali baru sebagai prioritas, selain pulau Dewata. Untuk pengembangan destinasi wisata tentu tidak terlepas kaitannya dengan identitas dan citra destinasi wisata yang berujung pada upaya peningkatan jumlah kunjungan wisatawan. Karena itu, perlu dilakukan kajian yang cukup spesifik untuk menelusuri konsep-konsep atau model-model pengembangan merek destinasi pariwisata melalui studi literatur untuk menemukan Kerangka Konseptual Identitas Merek dan Citra Merek Destinasi Pariwisata (Tourism Destination Brand Identity and Image Framework).

Dari berbagai aspek pengembangan destinasi pariwisata, tampaknya kajian mengenai merek destinasi (destination branding)pariwisata perlu mendapatkan perhatian khusus dan harus dilakukan secara cermat, karena Kementerian Pariwisata telahmenetapkan sepuluh destinasi prioritas yang disebut destinasi Bali baru sebagai unggulan, selain pulau Dewata. 
Kemenpar pada November 2017 lebih memfokuskan lagi pada empat destinasi prioritas (www.travel.kompas.com) yaitu Danau Toba, Borobudur, Mandalika (Nusa Tenggara Barat/NTB), dan Labuan Bajo (Nusa Tenggara Timur/NTT). Enam destinasi priortas yang lain adalah Tanjung Kelayang (Bangka Belitung), Tanjung Lesung (Banten), Kepulauan Seribu (DKI Jakarta), Bromo-Tengger-Semeru (Jawa Timur), Wakatobi (Sulawesi Tenggara), dan Morotai (Maluku).

Uraian pada latarbelakang penelitian ini menunjukkan keterkaitan yang erat antara identitas merek destinasi (yang dirancang) dengan citra merek destinasi (persepsi di mata wisatawan) sebagai hasil atau dampak dari tiga tahapan paralel dalam pengembangan merek destinasi (proses pelayanan, strategi komunikasi, dan infrastruktur fisik). Oleh karena itu, fokus dan permasalahan studi ini berkisar pada upaya-upaya untuk menemukan dan menelusuri model-model pengembangan merek destinasi pariwisata, identitas merek, citra merek, dan reputasi merek destinasi pariwisata yang komprehensif dan holistik, termasuk keterkaitannya dengan arsitektur merek destinasi pariwisata.

Berdasarkan fokus dan rumusan permasalahan studitersebut, maka tujuan penelitian ini adalah untuk:

1) menelusuri beragam konsep dan model pengembangan merek destinasi pariwisata (destination brand development), termasuk elemen-elemen atau komponen merek destinasi (destination brand components) dan arsitektur merek destinasi pariwisata;

2) menemukan dan merangkum model-model identitas dan citra merek destinasi pariwisata (tourism destination brand identity/image) beserta dimensi merek destinasi destination brand dimensions) dan berujung pada reputasi merek destinasi pariwisata (tourism destination brand reputation);

3) menyiapkan rancangan atau desain instrumen penelitian berdasarkan hasil penelusuran terhadap beragam konsep dan model, khususnya identitas merek dan citra merek destinasi pariwisata.

\section{Penelusuran Konsep dan Model}

Hasil penelusuran awal difokuskan terhadap beberapa konsep atau model seperti model Pengembangan Merek Destinasi disingkat DEBRA (Destination Brand Developonent), Hirarki Kebutuhan Wisatawan dalam Komponen Merek Destinasi (Destination Brand Component-Hierarchy Needs), model Piramida Manfaat Merek Destinasi (The Destination Brand Benefit Pyramid), serta model Identitas, Citra, dan Reputasi Merek Destinasi Pariwisata yang digunakan untuk perancangan atau desain Instrumen Penelitian. Sumber studi literatur adalah buku atau ebook, jurnal, dan hasil penelitian, terutama yang terbit pada era 2000an hingga terkini (2018).

\section{Kerangka Konseptual Model Identitas dan Citra Merek Destinasi Pariwisata}

Bila kita menelusuri beragam konsep dan model tentang brand, kita akan menemukan selain rangkaian terminologi brand identity, brand positioning, dan brand image, masih ada kelanjutannya yaitubrand reputations yang diungkapkan oleh beberapa pakar dalam tulisan atau riset mereka. 
Beberapa terminologi tersebut bila diterapkan dalam konteks destination branding, maka menjadi destination brand identity, destination brand positioningyang perlu diperluas menjadi destination brand communication untuk memancarkandestination brand image, dan destination brand reputation.Perluasan konsep destination brand positioningmenjadi komunikasi merek destinasi (destination brand communication) mencerminkan fokus kajian ini dari perpektif komunikasi. Gnoth (2007) merinci struktur merek destinasi menjadi dua dimensi yang masing-masing terdiri dari beberapa elemen. Dimensi pertama adalah Identitas Merek (Brand Identity) yang terdiri dari tiga elemen:symbolic, experiencial, dan functional. Dimensi kedua, Citra Merek (Brand Image) yang juga terdiri dari tiga dimensi:knowledge, experience, danstereotypes. Identitas merek akan menjadi kumpulan pengetahuan dan pengalaman wisatawan serta membentuk stereotipe mereka mengenai destinasi wisata.

Hanna dan Rowley (2011) mengenalkan model Manajemen Merek Kawasan Strategis (Strategic Place Brand Management). Kawasan atau tempat bisa identik dengan destinasi dalam konteks pariwisata. Mereka menyebutkan beberapa istilah, yakni arsitektur merek, identitas merek, artikulasi merek, dan komunikasi merek yang akhirnya membangun pengalaman merek (brand experience) terkait interaksi dengan destinasi pariwisata. Masih dalam kaitan identitas dan citra merek destinasi, penelitian Hsu dan Cai (2009) melalui model merek destinasi (model of destination branding) mengungkapkan kaitan antara pengetahuan (knowledge) yang dimulai dari pengenalan masyarakat terhadap keberadaan destinasi (brand awareness)dengan citra merek, berupa pemahaman yang mendalam (cognitive image) dan sikap wisatawan(affective image)terhadap berbagai atribut destinasi yang menimbulkan kepercayaan dan harapan terhadap destinati (brand trust), hingga loyalitas wisatawan terhadap destinasi (brand loyalty).

Selain penambahan konsep atau model destination brand reputation sebagai hasil dari upaya-upaya yang dilakukan dalam komunikasi merek, sebenarnya ada konsep yang lebih mendasar dalamperancangan awal strategi komunikasi merek, yaitu arsitektur merek (brand architecture) atau destination brand architecture.

Arsitektur merek (brand architecture) untuk konteks destinasi pariwisata menurutMorgan, Pritchard, dan Pride (2004:70-72)harus mencerminkan semua komponen utama merek destinasi, termasuk strategi positioning, alasan rasional (head) dan emosional (heart) terkait manfaat merek, asosiasi merek, dan kepribadian merek (brand personality). Arsitektur merek adalah jiwa dari cetak-biru sebagai panduan untuk membangun merek (brand building), pemasaran, dan pedoman bagi para manajer merek destinasi dalam menghadapi persaingan. Arsitektur merek penting untuk pengembangan suprabrands dan sub-brands destinasi. Contoh menarik yang bisa menjadi rujukan adalah Inggris (Britain) sebagai destination suprabrand dan sub- brands seperti Scotland, Wales, London, dan beberapa wilayah lain ketika VisitBritain dimulai pada 2002. Selain arsitektur merek Inggris, contoh lain yang menarik adalah arsitektur merek India dengan slogan Incredible India.

Hasil penelitian Ahuja (2014) merekomendasikan strategi Endorsed Brand Architecture dengan setiap negara bagian atau provinsi memiliki merek sendiri (Subtema) dengan empat kelompok keunikannya yaitu: Incredible Kerala (Nature), Incredible Goa (Beaches, Adventure), Incredible Rajasthan (Rich Heritage, Culture), dan Karnataka (Diversity). Semuanya berada di bawah merek payung atau merek induk bertema Incredible India dengan delapan keunikan, yaitu: sejarah, alam, keindahan, kuliner, spiritualitas, budaya, petualangan, dan hemat uang (murah). 
Sebagai rangkuman dari beberapa konsep atau model yang dijadikan rujukan seperti dikemukakan di atas, Gambar 6 berikut ini merupakan Kerangka Konseptual tentang Model Pengembangan Identitas dan Citra Merek Destinasi Pariwisata.Langkah strategis pertama adalahdestination brand architectureyang menjadi landasan dalam penetapan destination brand identitydandestination brand positioning (destination brand communication). Hasil yang diharapkan sebagai dampak dari komunikasi merek destinasi adalah destination brand image dan destination brand reputation.

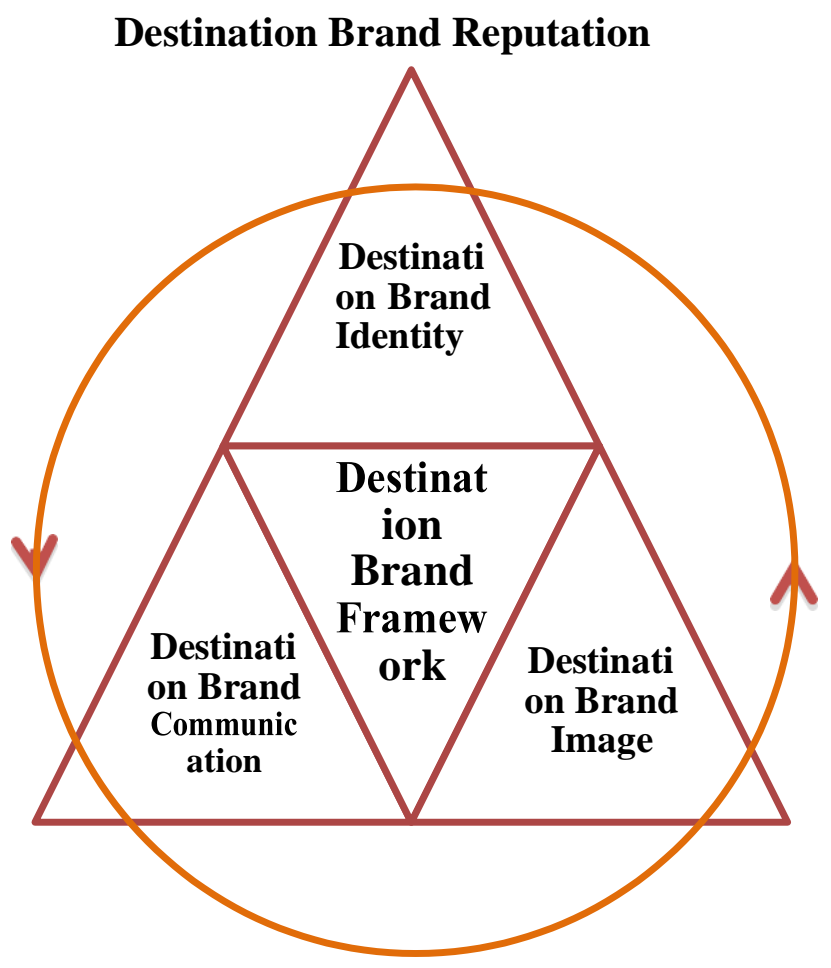

Destination Brand Architecture

Gambar 6. Kerangka Konseptual tentang Model Pengembangan Identitasdan Citra Merek Destinasi Pariwisata

Pada gambar tersebut, dalam Destination Brand Framework selain terdapat segitiga berisi tiga elemen yaitu Destination Brand Identity-Brand Communication-Brand Image, juga diawali dengan destination brand architecture dan diakhiridestination brand reputation dalam sebuah lingkaran atau putaran yang tiada henti.

Artinya, proses tersebut menjadi sebuah siklus yang berulang-ulang, dimulai dengan proses penting berupa perancangan destination brand architecture sebagai landasan bagi tiga elemen di dalam segitiga untuk menghasilkan destination brand reputation. 


\section{METODOLOGI PENELITIAN}

Berdasarkan uraian mengenai beberapa konsep atau model yang digunakan dalam penelitian ini dan Kerangka Konseptual tentang Pengembangan Identitas dan Citra Merek Destinasi Pariwisata, makabisa dilakukan perancangan atau penyusunan desain Instrumen Penelitian. Pengumpulan data untuk penelitian ini dilakukan melalui studi literatur terkait dengan tiga tujuan penelitian yang telah disebutkan terdahulu. Hasil penelitian ini adalah berupa pemaparan dan rangkuman beragam konsep dan model tentang identitas merek dan citra merek destinasi pariwisata yang menjadi Kerangka Konseptual beserta Desain Instrumen Penelitian. Hal ini tidak terlepas dari arsitektur merek destinasi yang diperlukan untuk komunikasi merek destinasi dalam membangun citra dan reputasi merek destinasi.

Tabel 1. Desain Instrumen Penelitian untuk

Model DEBRA dan TujuhKomponenMerek Destinasi Pariwisata

\begin{tabular}{|c|c|c|}
\hline No & Uraian Tiap Tahapan dan Komponen Merek & Keterangan \\
\hline 1. & $\begin{array}{l}\text { Budaya Perusahaan (corporate culture) } \\
\text { Pendefinisian nilai-nilai inti (core values) dan standarisasi } \\
\text { atau panduan perilaku yang dianjurkan (Kode Etik Perilaku). }\end{array}$ & $\begin{array}{l}\text { Rumusan budaya perusahaan } \\
\text { atau nilai-nilai inti (tata-nilai) } \\
\text { perusahaan pengelola }\end{array}$ \\
\hline 2. & $\begin{array}{l}\text { Analisis Persepsi atau Citra Merek Destinasi } \\
\text { Persepsi atau citra tentang merek destinasi dan citra merek } \\
\text { estinasi para pesaing di mata wisatawan maupun internal } \\
\text { karyawan level staf dan pimpinan. }\end{array}$ & $\begin{array}{l}\text { Data diperoleh dari hasil riset } \\
\text { persepsi wisatawan dan } \\
\text { internal }\end{array}$ \\
\hline 3. & $\begin{array}{l}\text { Rumuskan Janji Merek Destinasi (Destination Brand Promise) } \\
\text { atau Identitas Merek Destinasi (Destination Brand Identity) } \\
\text { Nilai-nilai fungsional dan emosional untuk memposisikan } \\
\text { merek destinasi dan pengembangan kepribadian merek } \\
\text { (brand personality) berbasis tahap } 1 \text { dan tahap } 2 .\end{array}$ & $\begin{array}{l}\text { Destination Brand } \\
\text { Promisesama dengan } \\
\text { Destination Brand Identity }\end{array}$ \\
\hline 4. & $\begin{array}{l}\text { Tiga Langkah Paralel (agar sesuai Identitas Merek Destinasi) } \\
\text { a) pengembangan proses pelayanan (service process } \\
\text { development) dari beberapa perusahaan atau pengelola } \\
\text { destinasi yang terlibat; } \\
\text { b) pengembangan strategi komunikasi; } \\
\text { c) pengembangan infrastruktur fisik. }\end{array}$ & $\begin{array}{l}\text { Untuk memastikan tiap titik } \\
\text { kontak (brand contacts) yang } \\
\text { dialami wisatawan (sebelum, } \\
\text { selama, setelah perjalanan) } \\
\text { sesuai identitas merek } \\
\text { destinasi yang dirancang }\end{array}$ \\
\hline 5. & $\begin{array}{l}\text { Eksekusi Komunikasi Eksternal } \\
\text { Menjaga keselarasankomunikasi eksternal dengan } \\
\text { komunikasi internal, pelatihan, dan pelayanan sesuai dengan } \\
\text { visi, nilai-nilai, dan janji merek. }\end{array}$ & $\begin{array}{l}\text { Konsistensi komunikasi } \\
\text { eksternal, komunikasi } \\
\text { internal, visi-misi, janji } \\
\text { merek, pelatihan, pelayanan, }\end{array}$ \\
\hline 6. & $\begin{array}{l}\text { Evaluasi atau Pengecekan ke Konsumen (Wisatawan) } \\
\text { Apakah janji merek sesuai dengan pelayanan di lapangan } \\
\text { (setiap proses). Menjaga tampilan visual dan fisik destinasi } \\
\text { yang mencerminkan identitas merek destinasi sesuai dengan } \\
\text { citra merek destinasi }\end{array}$ & $\begin{array}{l}\text { menciptakan citra merek } \\
\text { destinasi yang holistik } \\
\text { (Holistic Brand Image). }\end{array}$ \\
\hline 7. & $\begin{array}{l}\text { Pemantauan/Perbandingan Citra Merek di Mata Wisatawan } \\
\text { dan Identitas Merek Destinasi Pariwisata } \\
\text { Bila terjadi penyimpangan dari yang dicanangkan, perlu } \\
\text { dilakukan penyesuaian }\end{array}$ & $\begin{array}{l}\text { Penyesuaian di tiga langkah } \\
\text { paralel (proses pelayanan, } \\
\text { strategi komunikasi, dan } \\
\text { infrastruktur fisik). }\end{array}$ \\
\hline
\end{tabular}




\begin{tabular}{|r|l|l|}
\hline No & Uraian Tiap Tahapan dan Komponen Merek & Keterangan \\
\hline $\mathbf{8 .}$ & Tujuh Komponen Merek Destinasi Pariwisata & Review Komponen Merek: \\
& Rumusan visi destinasi, pemetaan para pemangku kepentingan & - visi destinasi \\
& (termasuk persepsi dan ekspektasi mereka), profil portfolio & - pemangku kepentingan \\
& produk andalan destinasi, rancangan strategi komunikasi dan & - portfolio produk andalan \\
& implementasi program, program-program untuk membangun & - strategi komunikasi \\
& citra (diferensiasi destinasi), memahami khalayak sasaran atau & - citra dan diferensiasi \\
& wisatawan, serta memantau dan evaluasi respon khalayak & - khalayak (wisatawan) \\
& wisatawan. & - respon khalayak/wisatawan \\
\hline
\end{tabular}

Untuk kepentingan operasional pengumpulan data penelitian, Tabel 1 di atas menyajikan Desain Instrumen Penelitian dari konsep pertama, yakni Model DEBRA dan Tujuh Komponen Merek Destinasi Pariwisata yaitu: rumusan visi destinasi, pemetaan para pemangku kepentingan (termasuk persepsi dan ekspektasi mereka), profil portfolio produk andalan destinasi, rancangan strategi komunikasi dan implementasi program, programprogram untuk membangun citra (diferensiasi destinasi), memahami khalayak sasaran atau wisatawan, serta memantau dan evaluasi respon khalayak wisatawan.

Operasionalisasi dari konsep atau model kedua (Komponen Merek Destinasi dan Tiga Dimensi Merek Destinasi) yang dipaparkan dalam penelitian ini tersaji padaTabel 2 berikut.

Tabel 2. Desain Instrumen Penelitian untuk

Destination Brand Component dan Tiga Dimensi Merek Destinasi

\begin{tabular}{|c|c|c|c|c|}
\hline \multirow[t]{2}{*}{ No } & \multirow{2}{*}{$\begin{array}{c}\text { The Brand Component-Need Hierarchy } \\
\text { Linkage (Pearce, 1991; Davis, 2002) }\end{array}$} & \multicolumn{3}{|c|}{ Tiga Dimensi Merek Destinasi } \\
\hline & & Nature/Alam & Culture/Budaya & History/Sejarah \\
\hline 1. & $\begin{array}{l}\text { Physiological Needs/Functional: } \\
\text { intrinsic benefits, satisfy promises } \\
\text { feature, relax, tangible, food. excitement, } \\
\text { stimulation. }\end{array}$ & $\begin{array}{l}\text { Fisik, lokasi } \\
\text { geografis, alam, } \\
\text { landscape, dan } \\
\text { icon utama }\end{array}$ & $\begin{array}{l}\text { Benda-benda } \\
\text { (artefak) } \\
\text { budaya }\end{array}$ & $\begin{array}{l}\text { Bangunan, } \\
\text { peninggalan } \\
\text { sejarah }\end{array}$ \\
\hline 2. & $\begin{array}{l}\text { Intangible: safety, security, convenience, } \\
\text { access, service. Reduce anxiety. }\end{array}$ & $\begin{array}{l}\text { Iklim/cuaca } \\
\text { bersahabat }\end{array}$ & $\begin{array}{l}\text { Nilai-nilai } \\
\text { kearifan lokal }\end{array}$ & $\begin{array}{l}\text { Perkembangan } \\
\text { destinasi }\end{array}$ \\
\hline 3. & $\begin{array}{l}\text { Relationship Needs: other destination } \\
\text { travelers, residents, WOM, ability to } \\
\text { form memories, experiences. Reduce } \\
\text { anxiety, affiliation, love, affection. }\end{array}$ & $\begin{array}{l}\text { Lokasi/posisi } \\
\text { geografis agar } \\
\text { interaksi } \\
\text { berkesan }\end{array}$ & $\begin{array}{l}\text { Kesantunan } \\
\text { warga, bahasa, } \\
\text { tradisi dan } \\
\text { adat-istiadat }\end{array}$ & $\begin{array}{l}\text { Sejarah dan } \\
\text { pengaruh } \\
\text { interaksi dari } \\
\text { pihak luar }\end{array}$ \\
\hline 4. & $\begin{array}{l}\text { Self-Esteem/Development Needs: } \\
\text { destination popularity, reputation, unique } \\
\text { experience. Need for status, respect, } \\
\text { recognition, achievement, self-growth, } \\
\text { curiosity, mastery, self-eficacy. }\end{array}$ & $\begin{array}{l}\text { Popularitas/ } \\
\text { keunikan icon, } \\
\text { lokasi\& alam } \\
\text { yang menjadi } \\
\text { kebanggaan }\end{array}$ & $\begin{array}{l}\text { Identitas suku } \\
\text { (etnik) yang } \\
\text { unik, diakui, } \\
\text { dihormati dan } \\
\text { menarik }\end{array}$ & $\begin{array}{l}\text { Cerita masa } \\
\text { gemilang } \\
\text { terkait lokasi } \\
\text { destinasi } \\
\text { pariwisata }\end{array}$ \\
\hline 5. & $\begin{array}{l}\text { Fulfillment Needs: customer loyalty, } \\
\text { revisit, reinforce self-expression, self- } \\
\text { actualization, flow of experience. }\end{array}$ & $\begin{array}{l}\text { Dayatarik alam } \\
\text { (fisik) untuk } \\
\text { aktualisasi-diri }\end{array}$ & $\begin{array}{l}\text { Dayatarik } \\
\text { budaya yang } \\
\text { penuh pesona }\end{array}$ & $\begin{array}{l}\text { Pesona masa } \\
\text { lalu yang } \\
\text { menarik }\end{array}$ \\
\hline
\end{tabular}


Tabel 2 tersebut menunjukkan keterkaitan dua konsep atau model yang digunakan dalam kajian ini, berupa kombinasi lima jenjang hirarki kebutuhan dalam komponen merek destinasi dari Pearce (1991) dan Davis (2002) dalam Balakrishnan (2008) serta model tiga dimensi merek destinasi dari Baker dan Cameron (2008) pada Tabel 2 di atas. Uraian pada tabel tersebut merupakan Desain Instrumen Penelitian yang menjadi dasar untuk penyusunan Panduan Wawancara Mendalam dan Panduan FGD.

Selanjutnya kombinasi dua konsep. Pertama, model lima jenjang piramida manfaat merek destinasi, mulai dari aspek fisik atau berwujud (tangible), hal-hal yang terasakan (intangible) dan emosi (psikologis), jalinan relasi, aktualisasi diri, prestise, hingga aspek simbolis. Kedua,lima hirarki kebutuhan wisatawan dalam komponen merek destinasi pariwisata berupa: Kebutuhan Fisiologis atau Fungsional (Physiological Needs/Functional); Kebutuhan Tak Berwujud (Intangible); Kebutuhan untuk Menjalin Hubungan (Relationship Needs); Kebutuhan akan Pengembangan Diri (SelfEsteem/Development Needs); dan Kebutuhan Pemenuhan Diri (Fulfillment Needs).Kesamaan kedua model tersebut bisa dicermati pada Tabel 3 yang digunakan sebagai panduan dalam penyusunan Instrumen Penelitian ini.

Tabel 3. Desain Instrumen Penelitian untuk

Destination Brand Benefit dan Destination Brand Component

\begin{tabular}{|c|l|l|}
\hline $\begin{array}{c}\text { Nomor } \\
\text { (Level) }\end{array}$ & $\begin{array}{c}\text { The Destination Brand Benefit } \\
\text { Pyramid (Morgan, Pritchard, Pride, 2004) }\end{array}$ & $\begin{array}{c}\text { The Brand Component - Need Hierarchy } \\
\text { Linkage(Pearce, 1991; Davis, 2002) }\end{array}$ \\
\hline $\mathbf{1 .}$ & $\begin{array}{l}\text { Level 1: Tangible, Verifiable, } \\
\text { Objective, Measurable Characteristics } \\
\text { of the Destination }\end{array}$ & $\begin{array}{l}\text { Physiological Needs/Functional: intrinsic } \\
\text { benefits, satisfy promises feature, relax, } \\
\text { tangible, food. excitement, stimulation. }\end{array}$ \\
\hline $\mathbf{2 .}$ & $\begin{array}{l}\text { Level 2: Benefits to the tourist (result } \\
\text { from the destination's features) }\end{array}$ & $\begin{array}{l}\text { Intangible: safety, security, convenience, } \\
\text { access, service. Reduce anxiety. }\end{array}$ \\
\hline $\mathbf{3 .}$ & $\begin{array}{l}\text { Level 3: Psychological rewards or } \\
\text { emotional benefits do tourists receive } \\
\text { by visiting the destination }\end{array}$ & $\begin{array}{l}\text { Relationship Needs: other destination } \\
\text { travelers, residents, WOM, ability to form } \\
\text { memories, experiences. Reduce anxiety, } \\
\text { affiliation, love, affection. }\end{array}$ \\
\hline $\mathbf{4 .}$ & $\begin{array}{l}\text { Level 4: The value mean for the } \\
\text { typical repeat visitor }\end{array}$ & $\begin{array}{l}\text { Self-Esteem/Development Needs: destination } \\
\text { popularity, reputation, unique experience. Need } \\
\text { for status, respect, recognition, achievement, } \\
\text { self-growth, curiosity, mastery, self-eficacy. }\end{array}$ \\
\hline $\mathbf{5 .}$ & $\begin{array}{l}\text { Level 5: The essential nature and } \\
\text { character of the destination brand }\end{array}$ & $\begin{array}{l}\text { Fulfillment Needs: customer loyalty, revisit, } \\
\text { reinforce self-expression, self-actualization, } \\
\text { flow of experience. }\end{array}$ \\
\hline
\end{tabular}

Uraian mengenai tiga komponen merek destinasi, yaitu brand identity, brand positioning, dan brand imagedapat dibaca pada Tabel 4 berikut ini. Komponen brand identity terdiri dari visi, misi, nilai-nilai, dan citra yang diharapkan menjadi dasar untukperancangan brand positioning (destination brand communication), dan brand imagemenuju reputasi merek destinasi yang diharapkan. 
Tabel 4. Desain Instrumen Penelitian untuk

Brand Identity, Brand Positioning, and Brand Image

\begin{tabular}{|r|l|l|}
\hline No & Uraian Tiap Tahapan dan Komponen Merek & Keterangan \\
\hline $\mathbf{1 .}$ & $\begin{array}{l}\text { Model Komponen Merek Destinasi terdiri dari tiga dimensi: } \\
\text { identitas merek pariwisata (Tourism Brand Identity), } \\
\text { Destination Brand Positioning, dan citra merek destinasi } \\
\text { pariwisata (Destination Brand Image) }\end{array}$ & $\begin{array}{l}\text { Integrasi dan keterkaitan } \\
\text { antara identitas, positioning, } \\
\text { dan citra destinasi pariwisata }\end{array}$ \\
\hline $\mathbf{2 .}$ & $\begin{array}{l}\text { Destination brand identity: visi, misi, nilai-nilai, logo, nama, } \\
\text { simbol, font, warna, dan persepsi yang diharapkan pengelola } \\
\text { merek agar tertanam di benak publik atau khalayak } \\
\text { (wisatawan). }\end{array}$ & $\begin{array}{l}\text { Identitas multidimensi dari } \\
\text { pemilik merek, berupa atribut } \\
\text { fisik maupun non-fisik }\end{array}$ \\
\hline $\mathbf{3 .}$ & $\begin{array}{l}\text { Destination brand positioning: berupa nilai proposisi yang } \\
\text { dikomunikasikan kepada khalayak sebagai } \\
\text { keunggulandestinasi pariwisata. }\end{array}$ & $\begin{array}{l}\text { Nilai atau atribut merek yang } \\
\text { ditetapkan agar tertanam di } \\
\text { benak wisatawan }\end{array}$ \\
\hline $\mathbf{4 .}$ & $\begin{array}{l}\text { Destination brand image: persepsi khalayak tentang merek } \\
\text { destinasi pariwisata. }\end{array}$ & $\begin{array}{l}\text { Persepsi atau asosiasi tentang } \\
\text { merek yang telah tertanam di } \\
\text { alam pikiran wisatawan }\end{array}$ \\
\hline
\end{tabular}

\section{DAFTAR PUSTAKA}

\section{Buku dan e-book}

Keller, K. L., 2013. Strategic Brand Management: Building, Measuring, and Managing Brand Equity. New Jersey: Pearson/Prentice Hall.

Morgan, N., Pritchard, A., and Pride, R. (eds.)., 2004. Destination Branding:Creating the unique destination proposition, Butterworth Heinemann, Oxford UK.

Moilanen, T \& Rainisto, S., 2009, How to Brand Nations, Cities and Destinations - A Planning Book for Place Branding, UK, Palgrave Macmillan.

\section{Artikel dan Jurnal}

Balakrishnan, M. S., 2008. Dubai - a Star in the East: A case study in strategic destination branding,Journal of Place Management and Development, Vol. 1 No. 1, pp. 62-91.

Balakrishnan, M. S., Ramzi N., Clifford L., 2008. Destination Brand Components. Working Paper Series. Univesity of Wollongong in Dubai (UOWD).

Gnoth, J., 2007. The Structure of Destination Brands: Leveraging Values. Tourism Analysis vo. 12, pp. 345-358.

Hanna, S., and Jennifer, R., (2011). Towards a strategic place brand-management model.Journal of Marketing Management, Vol. 27, No. 5-6, May, pp. 458-476.

Hsu, C., and Liping, C., 2009. Brand Knowledge, Trust and Loyalty: AConceptual Model of Destination Branding. International CHRIE Conference-Refereed Track. 
Iliachenko, E. Y., 2005. Exploring Culture, History and Nature as Tourist Destination Branding Constructs: The Case of a Peripheral Region in Sweden.Paper for The VIII Nordic-Scottish Conference on Rural and Regional Development in association withthe 14th Nordic Symposium in Tourism and Hospitality Research. Akureyri, Iceland, Sept. $22-25$.

Kavaratzis, M., and Ashworth, G. J., 2005. City Branding: An Effective Assertion Of Identity or a Transitory Marketing Trick?Tijdschrift voor Economische en Sociale Geografie, Vol. 96, No. 5, pp. 506-514.

Yousaf, A., Amin, I., Gupta, A., 2017, Conceptualising tourist based brand-equity pyramid: an application of keller brand pyramid model to destinations, Tourism and Hospitality Management, Vol. 23, No. 1, pp. 119-137.

\section{Sumber Online}

http://metrotvnews.com/ekonomi/mikro/nbw3ZJmb-pemerintah-targetkan-devisa-terbesardari-sektor-pariwisata

http://metrotvnews.com/ekonomi/mikro/JKRla47b-kunjungan-turis-asing-sepanjang-2017tak-capai-target

http://travel.kompas.com/read/2017/11/18/122700027/10-destinasi-bali-baru-4-destinasijadi-prioritas

https://travel.kompas.com/read/2017/09/15/124530327/bangga-indonesia-raid-2penghargaan-kompetisi-video-pariwisata-dunia-unwto 